\title{
AMICUS CURIAE DEMOCRÁTICO E O PROCESSO COLETIVO AMBIENTAL ${ }^{1}$
}

\author{
DEMOCRATIC AMICUS CURIAE AND THE ENVIRONMENTAL CLASS ACTION
}

\section{Magno Federici Gomes}

Estágio Pós-doutoral em Direito Público e Educação pela Universidade Nova de Lisboa-Portugal (Bolsa CAPES/BEX 3642/07-0). Estágios Pós-doutorais em Direito Civil e Processual Civil, Doutor em Direito e Mestre em Direito Processual, pela Universidad de Deusto-Espanha (Bolsa da Cátedra UNESCO e do Gobierno VascoEspanha). Mestre em Educação pela PUC Minas.

\section{Leandro José Ferreira}

Mestrando em Direito Ambiental e Desenvolvimento Sustentável na Escola Superior Dom Helder Câmara. Especialista em Direito Processual pela PUC/MG. Bacharel em Direito. Advogado militante.

\section{Resumo}

A pesquisa busca analisar o instituto do amicus curiae no âmbito do processo coletivo nacional e o princípio da participação popular. O problema que se pretende resolver é se o amicus curiae apresenta-se como instrumento adequado para propiciar a participação e a fiscalização popular no processo coletivo ambiental. Foram utilizados na realização desta pesquisa o método vertente jurídico-teórico e o raciocínio dedutivo, com técnica de pesquisa bibliográfica. Ao final da pesquisa, foi possível evidenciar que o amicus curiae se apresenta como instrumento parcialmente democrático, sendo necessário 0 desenvolvimento e 0 aperfeiçoamento de um novo agente democrático que, de modo mais adequado possibilite uma melhor e mais afinada participação e fiscalização popular em demandas ambientais.

Palavras-Chave: Amicus curiae; Ação civil pública ambiental; Ação popular ambiental; Atuação democrática; Política pública judicial.

\footnotetext{
1 Trabalho financiado pelo Projeto FAPEMIG n 5236-15, resultante dos Grupos de Pesquisas (CNPQ): Regulação Ambiental da Atividade Econômica Sustentável (REGA), NEGESP, Metamorfose Jurídica e CEDIS (FCT-PT).
} 


\begin{abstract}
The research seeks to analyze the institute of the amicus curiae in the scope of the national collective process and the principle of popular participation. The problem to be solved is whether the amicus curiae is an adequate instrument to foster participation and popular control in the environmental collective process. The juridicaltheoretical approach and deductive reasoning were used in this research, with a bibliographic research technique. At the end of the research, it was possible to show that the amicus curiae presents itself as a partially democratic instrument, and it is necessary to develop and improve a new democratic agent that, in a more adequate way, allows a better and more well-known participation and popular control in environmental demands.
\end{abstract}

Keywords: Amicus curiae; Environmental public civil action; Popular environmental action, Popular Participation and Surveillance.

\title{
1. INTRODUÇÃO
}

A partir de meados dos anos de 1970, o meio ambiente adequado à sadia qualidade de vida vem se tornando uma das pautas mais assíduas da comunidade internacional. A preocupação com a proteção ambiental leva em conta a busca por mecanismos capazes de reger, ou de ao menos tentar conduzir, a humanidade a novos caminhos hábeis a propagar a proteção do bem ambiental para as presentes e futuras gerações.

No Brasil, a partir de 1988, o direito ao meio ambiente equilibrado à sadia qualidade de vida é elevado ao status de norma de direito fundamental, onde a proteção ambiental passa a ser responsabilidade do Estado e também de toda a coletividade. Assim, o direito ao meio ambiente saudável apresenta-se como um dever/direito da coletividade e do Estado, pois todos têm direito ao meio ambiente saudável e a todos é atribuído o dever de protegê-lo.

Nessa senda, a participação da sociedade na promoção e na proteção do meio ambiente equilibrado à sadia qualidade de vida torna-se uma premissa inarredável e de necessária e indispensável concretização. O Estado Democrático de Direito permite que toda a sociedade participe, de forma deliberativa, das decisões emanadas no âmbito do Poder Executivo, do Poder Legislativo e do Poder Judiciário.

Sobre o viés da participação popular, o presente ensaio, portanto, visa dedicar-se ao estudo do instituto do amicus curiae e seus desdobramentos no cenário nacional, especialmente no que tange à averiguação da possibilidade de sua 
intervenção no processo coletivo ambiental. Sob a ótica da Ação Civil Pública (ACP) e da Ação Popular (AP) será apurada a (in) existência de contribuição do amicus curiae no que tange à legitimidade democrática, de modo a possibilitar o debate judicial em prol de uma decisão justa e equânime.

Espera-se responder o seguinte problema: o amicus curiae representa legítimo instrumento de participação e fiscalização democrático no âmbito do processo coletivo ambiental?

A pesquisa se justifica na medida em que é imprescindível para o meio acadêmico e para a sociedade, compreender de forma mais precisa e adequada o instituto do amicus curiae, principalmente no que tange ao seu uso na seara do processo coletivo ambiental. O objetivo é sugerir formas mais efetivas de participação social no processo civil ambiental, sugerindo políticas públicas judiciais que fomentem a democracia.

Nessa órbita, para a elucidação da investigação foram utilizados o método vertente jurídico-teórico e o raciocínio dedutivo, com a técnica de pesquisa bibliográfica e documental. $\mathrm{O}$ estudo partirá da realização de um breve panorama sobre a origem histórica do amicus curiae, seus desdobramentos no cenário internacional e nacional. Dessa forma, um cotejo sobre alguns pontos do amicus curiae do sistema norte americano será realizado até o seu surgimento no sistema jurídico brasileiro.

No capítulo seguinte, serão apresentadas as nuances e desdobramentos do amicus curiae já no cenário do Código de Processo Civil de 2015 (CPC/2015).

No terceiro capítulo será realizada uma exposição da ACP ambiental e suas especificidades no cenário jurídico brasileiro, seus requisitos e discussões sobre sua aplicação, inclusive em análise ao tema deste trabalho.

Após, será apresentado estudo sobre a AP ambiental, de modo a levantar as discussões mais sensíveis sobre esse remédio constitucional de envergadura estritamente democrática que permite aos cidadãos fiscalizar a Administração Pública e proteger o meio ambiente equilibrado.

Por fim, no quinto capítulo, os temas anteriores serão condensados no intróito de desvelar se o amicus curiae pode, ou não, ser considerado uma ferramenta de concretização e manifestação democrática no âmbito do processo coletivo ambiental, pois trata-se de instituto que permite a intervenção de terceiro interessado na lide ambiental. 


\section{ORIGEM HISTÓRICA E DESDOBRAMENTOS DO AMICUS CURIAE}

A doutrina assevera que o amicus curiae tem origem no direito internacional, contudo, não existe uma coerência exata sobre onde tenha se dado o nascimento dessa figura processual, sendo que boa parte da doutrina admite que sua gênese tenha ocorrido no direito romano, "o instituto do amicus curiae tem sua origem ainda no direito romano, tendo se desenvolvido particularmente no direito medieval inglês" (CAMBI; DAMASCENO, 2015, p. 657). Outros teóricos apontam que o instituto tenha seu nascedouro em Roma, "da análise da figura dos amici curiae temos que sua origem é duvidosa: uma primeira tese aponta que teve início em Roma" (SILVA, 2018, p. 660). Nota-se, assim, que a origem do amicus curiae, portanto, é controversa na doutrina.

No direito romano existia a figura do consilliarius romano, que era uma pessoa convocada pelos magistrados para formular posição frente ao caso concreto. Essa figura era assemelhada ao amicus curiae, que no direito romano advinha no processo como mero colaborador do magistrado naquelas demandas que exigiam conhecimentos para além do jurídico.

Por outro lado, no direito inglês "[...] desde à origem, o amicus curiae poderia comparecer espontaneamente perante o juízo e fornecer elementos de acordo com - seu próprio convencimento, sem a obrigatoriedade da neutralidade" (FIGUEIREDO, 2017, p. 241).

Ainda que exista na doutrina algum grau de controvérsia quanto à origem do amicus curiae, quanto ao seu desenvolvimento e aprimoramento parece não haver maiores contradições, "[...] independente de uma certeza ou exatidão quanto à origem, é consente ter sido no direito norte-americano que 0 instituto se desenvolveu, aprimorou-se e atingiu visibilidade no cenário internacional" (MATTOS, 2011, p. 15).

Ante as considerações apontadas, é possível indicar a existência de um consenso doutrinário quanto ao fato de que o desenvolvimento e aperfeiçoamento do amicus curiae se deu no âmbito do direito norte americano, quando foi oportunizada sua intervenção no ano de 1812 em razão do julgamento do caso "The 
Schooner Exchange vs. Mc Fadden".2

É sábio considerar que o amicus curiae obteve maior aceitação e desenvolvimento nos Estados Unidos da América (EUA) em razão do sistema jurídico adotado naquele país, qual seja, o modelo do stare decisis, modelo onde predomina a força e o respeito aos precedentes jurisprudenciais que se formam a partir de determinados casos concretos e que possuem força vinculante em relação aos casos análogos posteriores.

No mesmo sentido, Cabral afirma que: "o amicus curiae ou 'amigo da corte' é um instituto desenvolvido predominantemente no common law em razão da força vinculativa dos precedentes judiciais [...]" (CABRAL, 2016, p.330). Sendo oportuno contextualizar que o sistema da common law, é aquele que adota os costumes como a principal fonte do direito, por meio de precedentes firmados pelos tribunais.

Noutra vertente é o sistema da civil law, segundo o qual as leis foram e ainda são as principais fontes do direito. No Brasil, o primeiro sinal de existência do amicus curiae ocorreu no ano de 1978, com a edição da Lei no 6.616/78, que fez incluir o art. 31 na Lei no 6.385/76, que dispôs sobre a Comissão de Valores Mobiliários (CVM). ${ }^{3}$

Verifica-se por meio do dispositivo supramencionado que a nomenclatura amicus curiae não foi expressamente adotada pelo dispositivo legal. Contudo, o ato de possibilitar a intimação da CVM para oferecer parecer no âmbito dos processos judicias, naqueles casos de sua competência, exprime o sentido que é próprio do amicus curiae.

Posteriormente, a Lei ํㅜ 8.197/91, em seu artigo 2oㅡ, também passou a prever a intervenção da União Federal como terceiro. No entanto, a citada lei foi subsequentemente alterada pela Lei $n^{\circ}$ 9.469/97, que em seu artigo $5^{\circ}$ permitiu a intervenção da União em algumas situações. ${ }^{4}$

Mais uma vez, é importante destacar que o preceito legal não previu expressamente a nomenclatura amicus curiae, mas, ao permitir a intervenção da União Federal naqueles casos, a norma evidenciou premissas conexas à figura de

\footnotetext{
2 Para maiores aprofundamentos ver: KRISLOV apud BUENO, 2012, p. 116.

${ }^{3}$ Art. 31. Nos processos judiciários que tenham por objetivo matéria incluída na competência da Comissão de Valores Mobiliários, será esta sempre intimada para, querendo, oferecer parecer ou prestar esclarecimentos, no prazo de quinze dias a contar da intimação (BRASIL, 1976).

4 "Art. 5 da Lei no 9.469/97: A União poderá intervir nas causas em que figurarem, como autoras ou rés, autarquias, fundações públicas, sociedades de economia mista e empresas públicas federais" (BRASIL, 1997).
} 
tal instituto.

Mais adiante, a Lei no 8.884/94, em seu artigo 89, garantiu ao Conselho Administrativo de Defesa Econômica (CADE), a intervenção, como assistente, nas demandas que apresentavam alguma discussão envolvendo a aplicação da citada lei. ${ }^{5}$ Repita-se, o dispositivo legal não contemplou a expressão amicus curiae.

$\mathrm{Na}$ visão de Cabral, a figura do amicus curiae também foi contemplada no âmbito administrativo. Assim dispõe o autor: "o instituto encontra-se presente também nos processos administrativos" (CABRAL, 2003, p.116). Na visão do autor, a Lei no 9.784/99, responsável por regulamentar o procedimento administrativo federal, permitiu, em seus artigos 31 e 32, a intervenção do amicus curiae naqueles debates mais relevantes, ao dispor que: "[...] poderá o órgão competente admitir a intervenção do amicus e até realizar audiência pública para permitir debates mais amplos sobre a matéria discutida no processo" (CABRAL, 2003, p. 116).

O amicus curiae também foi contemplado no âmbito dos Juizados Especiais Federais, conforme norma do art. $14, \S 7^{\circ}$, da Lei $10.259 / 01$, que em sua parte final regulamenta que: "[...] eventuais interessados, ainda que não sejam partes no processo, poderão se manifestar, no prazo de trinta dias (BRASIL, 2001).

No entanto, em que pese todo o desenvolvimento histórico apontado até o momento, a doutrina assinala que o ápice do amicus curiae no direito brasileiro se deu com a edição da Lei no 9.868/99, que regulamentou os processos de Ação Direta de Inconstitucionalidade (ADI) e Ação Declaratória de Constitucionalidade (ADC) perante o Supremo Tribunal Federal (STF). Nesse sentido, Costa ensina que com a Lei no 9.868/1999, "[...] o instituto do amicus curiae passou a ser discutido com mais ênfase" (COSTA, 2013, p. 357).

Logo em sequência, a Lei no 9.882/99, que veio regulamentar os processos de Arguição de Descumprimento de Preceito Fundamental (ADPF), em consonância com a Lei $n^{\circ} 9.868 / 99$, autorizou em seu artigo $6^{\circ}, \S 2^{\circ}$, que a critério do relator, poderão ser autorizadas a sustentação oral e a juntada de memoriais mediante requerimento daqueles interessados no processo.

A partir dessa análise histórica do instituto do amicus curiae foi possível evidenciar que sua inserção no sistema jurídico brasileiro foi se dando de forma paulatina, até ser introduzido de forma expressa no âmbito do processo civil

\footnotetext{
${ }^{5}$ Art. 89. Nos processos judiciais em que se discuta a aplicação desta lei, o CADE deverá ser intimado para, querendo, intervir no feito na qualidade de assistente (BRASIL, 1994).
} 
nacional, conforme passaremos a explanar em sequência.

\section{O AMICUS CURIAE NA SISTEMÁTICA DO CÓDIGO DE PROCESSO CIVIL DE 2015}

O CPC/2015 inaugurou uma nova visão de sistema processual no cenário nacional, representando verdadeiro avanço epistemológico no que tange à implementação de preceitos e princípios constitucionais tendentes a permear e a permitir uma maior e mais adequada participação social, no claro objetivo de entregar maior legitimidade à função jurisdicional.

Em verdade, o CPC/2015 veio confirmar e adequar o sistema processual civil aos direitos e garantias fundamentais expressos na Constituição Federal de 1988 (CF/88). De forma contunde o CPC/2015 supera a técnica de processo como relação jurídica onde Chiovenda, ao trabalhar as bases da ciência do direito processual civil, apresentou o seguinte conceito: "o processo civil contém uma relação jurídica. É a ideia já inerente ao judiciário romano: e a definição dada por ele por nossos processadores medievais: o Juiz agradeceu a três pessoas, iudicis, acioris et rel" (CHIOVENDA, 1922, p. 109, tradução própria) 6 .

Nesse aspecto, a ciência processual avança rumo ao processo democrático constitucional, justamente por ser aquele que tem suas bases elementares fixadas no núcleo das garantias fundamentais expressas na CF/88. Trata-se, portanto, de uma técnica processual com vistas a constitucionalizar o processo, que visa garantir a implementação de direitos e garantias fundamentais mediante a construção participativa do provimento final, onde as partes são chamadas a participar do processo e a produzir a decisão final.

Assim, pode-se auferir que o CPC/2015 tenta tornar o processo mais democrático, mais acessível e sensível às manifestações sociais no cumprimento das garantias constitucionais, onde as partes são chamadas a todo o tempo à autocomposição, por meio da conciliação e da mediação, em prestígio ao paradigma jurídico do discurso deliberativo dialético.

Noutra vertente, percebe-se que o CPC/2015 encaminhou uma aproximação

\footnotetext{
${ }^{6}$ Tradução do original: "El proceso civil contiene una relación jurídica. Es la idea ya inherente al judío romano: y la definición dada por él por nuestros procesadores medievales: el Juez agradeció a tres personas, iudicis, acioris et rei".
} 
entre os sistemas da civil law e da commaw law, instituindo a força vinculante dos precedentes no direito nacional. Observa-se o direcionamento ao sistema de padronização do direito pela valoração dos precedentes, com a inauguração de um discurso de aplicação de precedentes judiciais, qual seja, um modelo de precedentes vinculantes.

Nessa senda, é possível antecipar duas sucintas conclusões: a primeira é a de que o CPC/2015 busca entregar bases democráticas nucleares ao processo civil, comprometido com os princípios e regras emanadas da $\mathrm{CF} / 88$, aptas a reger o devido processo legal (contraditório; ampla defesa; isonomia; fundamentação das decisões). Em segundo lugar, infere-se que a nova norma processual civil amplia a força dos precedentes, de modo a autorizar uma maior padronização do direito por meio daqueles julgamentos exarados em sede de recursos repetitivos, tendentes a orientar ao máximo a atuação jurisdicional.

Diante desse quadro, para entregar maior legitimidade aos órgãos do poder judiciário, que agora são responsáveis por emitir decisões vinculantes, o instituto do amicus curiae surge como uma figura típica de concretização da participação social na formação dos precedentes.

Afigura-se que o amicus curiae enseja e empresta maior espaço de discussão na formação dos precedentes judiciais, onde a análise das razões e contrarrazões postas em discussão no processo possam ser deliberadas de maneira cooperativa e cooparticipativa, entre o julgador, as partes e a sociedade, haja vista que no Estado Democrático de Direito, que se caracteriza pelo respeito às liberdades civis, pelo respeito aos direitos humanos, e pela deferência dos direitos e garantias fundamentais consagrados no texto constitucional, a participação social é princípio fundamental de regência do Estado.

O amicus curiae está disciplinado no artigo 138 do CPC/2015. A codificação traz algumas novidades ao instituto em relação às normas esparsas que já 0 disciplinavam no cenário nacional

A primeira questão que o $\mathrm{CPC} / 2015$ parece ter resolvido é no que tange à natureza do amicus curiae, haja vista que boa parte da doutrina divergia quanto à sua natureza jurídica. Tal instituto era classificado como sendo hipótese de intervenção de terceiros, intervenção atípica de terceiros, terceiro especial, assistente e até mesmo auxiliar da justiça (MATTOS, 2011). Para sanar as discussões levantadas até o momento o CPC/2015 tratou de disciplinar a figura do 
amicus curiae como intervenção de terceiros.

$\mathrm{O}$ artigo 138, caput do referido ordenamento traz algumas novidades e expressões que precisam ser melhor compreendidas. Afigura-se que o juiz e o relator poderão decidir sobre a possibilidade de intervenção do amicus curiae, o que demonstra que o instituto poderá ser aceito em todas as instâncias do Poder Judiciário e não somente nas Cortes Superiores como era anteriormente.

Outra questão de relevo está no fato de o dispositivo permitir a participação de pessoa natural ou jurídica, órgão ou entidade especializada com representatividade adequada. A novidade está em permitir a intervenção de pessoa natural no bojo do processo, o que anteriormente era impensável. Assim, a doutrina compreende essa possibilidade como benéfica ao Estado Democrático de Direito nos seguintes termos: "com a vigência do CPC de 2015 tornou-se mais esclarecida a questão, uma vez que a norma autoriza expressamente a participação de pessoas naturais na condição de amicus curiae" (FIGUEIREDO, 2017, p. 253).

No mesmo sentido, a doutrina destaca que não se trata de admitir no âmbito do processo qualquer pessoa física ou jurídica como amicus curiae, ao contrário, "é necessário que o terceiro (natural ou jurídica) possua representatividade adequada, conforme condição prevista no próprio art. 138" (FIGUEIREDO, 2017, p. 253).

Compreende-se que a abertura do canal de participação de pessoas naturais e jurídicas afeiçoa-se aos ditames constitucionais que asseveram a necessidade de acesso democrático ao processo para legitimar a atuação jurisdicional. É importante destacar que os preceitos constitucionais devem ser abertos à interpretação de toda a sociedade conforme sustenta Häberle, "no processo de interpretação constitucional estão potencialmente vinculados todos os órgãos estatais, todas as potências públicas, todos os cidadãos e grupos [...]" (HÄBERLE, 2015, p. 27).

Percebe-se, contudo, que a intervenção do amicus curiae deve ser limitada à vinculação da matéria. Em outras palavras, a pessoa ou entidade chamada ou autorizada a intervir na demanda deve ser profundamente conhecedora da matéria discutida no caso concreto, pois o terceiro interventor tende a contribuir para o esclarecimento da demanda, não se admitindo, portanto, que alguém ofereça esclarecimentos sobre aquilo que não se conhece.

Outro requisito necessário para que seja autorizada a intervenção do amicus curiae é o da representatividade adequada, que revela imperiosa necessidade de 
que o interessado demonstre claramente qual o motivo de sua intervenção e de que modo seu interesse institucional relaciona-se com a lide. (BUENO, 2015, p.158).

Em relação aos requisitos previstos no artigo 138, caput, quais sejam: 'relevância da matéria'; 'especificidade do tema' e 'repercussão social', algumas digressões são necessárias. Parece que tais requisitos desdobram-se entre si de forma conjugada, de modo a formar uma rede de situações concretas passíveis de intervenção pelo amicus curiae. Tais situações consubstanciam exatamente naqueles casos sensíveis que expressam maior excitabilidade nacional.

Constata-se que as demandas que tratam sobre os direitos e garantias fundamentais são, em certa medida, os objetos principais de discussão do amicus curiae. Demandas relacionadas ao acesso à educação, à saúde, ao meio ambiente equilibrado, à assistência e à previdência social são alguns exemplos de demandas que reclamam a participação do amicus curiae em razão da natureza de direito fundamental.

Conforme preceitua a doutrina, algumas demandas privadas podem carregar preceitos fundamentais que envolvam direitos de toda à sociedade. Desse modo, a concepção de interesse unicamente privado do processo aos poucos vai sendo afastada para ceder lugar há uma concepção coletiva de demanda, que deve permitir a participação de toda a sociedade na ação posta em discussão.

Assim, cabe ressaltar que o amicus curiae estará autorizado a intervir em toda e qualquer demanda de natureza relevante para a sociedade. A especificidade do tema e a repercussão geral da lide poderão autorizar a intervenção do amicus curiae na medida em que a modulação dos efeitos da decisão gerará implicações e aplicações para toda a sociedade. Não podendo se falar, portanto, em rol taxativo de demandas que admitam, ou não, a intervenção do amicus curiae, quando, em verdade, caberá ao juiz ou ao relator decidir sobre a possibilidade, ou não, da intervenção diante de determinado caso concreto.

No entanto, Cabral (2016, p. 336), afirma que em determinadas demandas a intervenção do amicus curiae é imprescindível para o concreto alcance social do processo, tais como: questões sociais referentes à saúde, educação, gestão de verba pública e orçamento participativo, aos quais é possível acrescentar as questões sobre o meio ambiente equilibrado à sadia qualidade de vida.

Sem embargo, cabe também ao juiz e ao relator a tarefa de definir quais serão os poderes do amicus curiae na demanda, sendo certo que, o juiz e o relator, 
mediante análise das razões e contrarrazões que o caso concreto envolve, após ouvir as partes, poderão deliberar sobre a extensão dos poderes do amicus curiae.

Noutra vertente, é importante destacar que a intervenção do amicus curiae não tem o poder de alterar a competência para o julgamento da demanda conforme previsto no $\S 1^{0}$ do artigo 138 , do CPC/2015. Outro ponto sensível em relação à codificação do instituto está na possibilidade recursal. Regra geral, o amicus curiae não está autorizado a interpor recursos, ressalvadas as hipóteses de embargos de declaração e da decisão que julgar o incidente de resolução de demandas repetitivas.

Em suma, é possível considerar que a codificação do amicus curiae foi benéfica ao processo civil, pois regulamentou, no âmbito da jurisdição civil, instituto tipicamente democrático, hábil a consubstanciar a participação e a fiscalização da sociedade de todo provimento jurisdicional que envolva direitos sensíveis à comunidade.

\section{A AÇÃO CIVIL PÚBLICA AMBIENTAL}

Ao trabalhar a ACP deve-se considerar que trata-se de um 'remédio constitucional', apesar de não constar expressamente no rol do art. 5ำ da CF/88. Embora não disciplinado no dispositivo apontado alhures, tal remédio esta devidamente disciplinado na Lei 7.347/85, que regulamenta a ACP de responsabilidade por danos causados ao meio ambiente; ao consumidor; a bens e direitos de valor artístico; estético; histórico; paisagístico; a qualquer outro interesse difuso ou coletivo; por infração à ordem econômica; à ordem urbanística; à honra e à dignidade de grupos raciais; étnicos; religiosos; ao patrimônio público e social (BRASIL, 1985).

Nesse mesmo sentido, é o magistério de Rodrigues: "[...] a ação civil pública faz parte do cotidiano do brasileiro, que já a reconhece como o instrumento típico de proteção jurisdicional dos interesses coletivos (em sentido lato)" (RODRIGUES, 2007, p. 248).

No entanto, verifica-se que a concreta normatização da ACP tenha se dado na esfera da Lei 7.347/85 e posteriormente no âmbito constitucional, pois em 1988 a CF/88, ao disciplinar as funções institucionais do Ministério Público (MP) no art. 129, III, entregou ao órgão a missão de promover a ação civil pública para a proteção do 
patrimônio público e social, do meio ambiente e de outros interesses difusos e coletivos.

Verifica-se, portanto, a importância desse singular instrumento de proteção aos direitos difusos. Conforme preceitua o art. 1º, inciso I, da Lei 7.347/85, um dos objetivos da ACP é promover a proteção e a responsabilização daqueles danos causados ao meio ambiente, uma vez que o meio ambiente equilibrado, a fim de proporcionar às pessoas a sadia qualidade de vida, é direito fundamental insculpido no art. 225 da CF/88 que deve ser garantido e protegido por todos, inclusive para, e pelas presentes e futuras gerações.

Importante considerar que ao longo de sua edição a Lei da ACP veio sofrendo algumas alterações em relação ao texto original, como exemplo é possível destacar a Lei 8.078/90 que disciplina o Código de Defesa do Consumidor (CDC). No entanto, as alterações não comprometeram o objeto e a funcionalidade da ACP, ao contrário, houve uma verdadeira aproximação de conceitos para a formação do chamado sistema processual coletivo. Nas palavras de Rodrigues, "A simbiose entre os dois sistemas (LACP, art. 21 e CDC, arts. 90 e 117) formam o sistema processual coletivo" (RODRIGUES, 2007, p. 281).

Os legitimados ativos estão elencados no art. 5으 da Lei 7.347/85 e no art. 82 do CDC. Nesse ponto em específico, a doutrina assevera que houve uma absorção do art. 5ำ pelo art. 82, sob dois fundamentos: o primeiro é de que rol apresentado pelo art. 82 é mais completo e enumera um maior e mais qualificado número de legitimados; o segundo é que o art. 82 superou o art. 5ำ por ser mais recente.

Ainda assim, destacando aqueles preceitos da Lei 7.347/85, Moreira destaca quem são os legitimados ativos da ACP: "[...] Ministério Público, União, Estados e Municípios, autarquias, empresas públicas, fundações, sociedades de economia mista e associações civis constituídas há mais de um ano [...] (MOREIRA, 1995, p.50).

Verifica-se que o extenso rol de legitimados ativos para a propositura da ACP enseja e possibilita um maior e mais qualificado acesso à proteção daqueles interesses transindividuais, que são entendidos como aqueles direitos que ultrapassam a esfera do individual. São os chamados direitos difusos, os direitos coletivos e os direitos individuais homogêneos.

O direito difuso se apresenta como sendo aquele direito de natureza transindividual, que possui um objeto indivisível, de titularidade indeterminada, 
relacionados por circunstâncias de fato, são direitos que pertencem a todos e a ninguém ao mesmo tempo.

Já os direitos coletivos são aqueles direitos transindividuais, de natureza indivisível, pertencentes a uma determinada classe de indivíduos ligados entre si por uma relação jurídica. Nos direitos coletivos, os titulares do direito são identificáveis. Fiorillo destaca: "[...] por conta da natureza do direito coletivo, esses titulares (que estão ligados por uma relação jurídica entre si ou com a parte contrária) são identificáveis" (FIORILLO, 2013, p. 45). Os direitos individuais homogêneos são aqueles decorrentes de uma mesma causa, onde os sujeitos são invariavelmente mais de um e determinados ou determináveis.

Uma vertente recente, que se formou com mais ênfase a partir dos anos de 1970, vem despertar a necessidade de tutelas voltadas para o coletivo e não somente para aqueles interesses individuais. Uma série de fatores econômicos e sociais levou o processo a preocupar-se em resguardar e proteger direitos coletivos, para além de uma proteção meramente individual.

Conforme sustentam Cappelletti e Garth: "interesses difusos são interesses fragmentados ou coletivos, tais como o direito ao ambiente saudável, ou à proteção do consumidor" (CAPPELLETTI; GARTH, 1988, p. 26).

Em algumas demandas o poluidor ou o fornecedor podem se mostrar mais fortes (técnica e economicamente) do que um simples indivíduo, motivo pelo qual se faz necessário equiparar as forças entre pólo ativo e pólo passivo, entregando ao pólo passivo órgãos e entidades dotadas de maior poder e representação do que aquele indivíduo singular. Nesse Sentido, Cappelletti e Garth citando Galanter, atestam que: "o professor Galanter desenvolveu uma distinção entre o que ele chama de litigantes "eventuais" e "habituais", baseado na freqüência de encontros com o sistema judicial” (CAPPELLETTI; GARTH, 1988, p. 25/26) ${ }^{7}$.

Nesse enfoque, portanto, é possível considerar que a legitimação de

\footnotetext{
${ }^{7}$ Ele sugeriu que esta distinção corresponde, em larga escala, à que se verifica entre indivíduos que costumas ter contatos isolados e pouco freqüentes com o sistema judicial e entidades desenvolvidas, com experiência judicial mais extensa. As vantagens dos "habituais", de acordo com Galanter, são numerosas: 1) maior experiência com o direito possibilita-lhes melhor planejamento do litígio; 2) o litigante habitual tem economia de escala, porque tem mais casos; 3) o litigante habitual tem oportunidades de desenvolver relações informais com os membros da instância decisora; 4) ele pode diluir os riscos da demanda por maior número de casos; e 5) pode testar estratégias com determinados casos, de modo a garantir expectativa mais favorável em relação a casos futuros. Parece que, em função dessas vantagens, os litigantes organizacionais são, sem dúvida, mais eficientes que os indivíduos (CAPPELLETTI; GARTH, 1988, p. 25/26).
} 
litigantes organizacionais pretende entregar maior força aos combatentes que buscam a proteção dos direitos difusos e coletivos que são prezados pela coletividade, a exemplo do meio ambiente saudável. No que tange aos legitimados passivos para a ACP, parece haver, na doutrina, dificuldades na sua definição, justamente em razão da própria natureza metaindividual dos direitos judicializados.

Noutro giro, Mancuso destaca a possibilidade da utilização do sistema adotado nos EUA, qual seja, "réu na ação de classe" ${ }^{8}$. Assim o Mancuso afirma que: "no sistema norte americano existe, pela regra 23 (a) (3) das Federal Rulesof Civil Procedure, a possibilidade de a ação coletiva ser movida contra ou em face de uma classe (a chamada defendant class action), [...]" (MANCUSO, 2014, p. 200).

Importante destacar que essa possibilidade não se trata de uma mera utilização de método alienígena indiferente à realidade brasileira, haja vista que o microssistema de processo coletivo adotado no Brasil, em especial a ACP, foi reproduzido, guardadas as devidas proporções acerca da realidade fática de cada país e de cada sistema jurídico, a partir do sistema norte americano. Assim, confirma Rodrigues: "uma rápida folheada na Regra 23 da Legislação Federal Processual Civil americana denunciara com precisão a fonte do legislador brasileiro" (RODRIGUES, 2007, p. 256).

A class action é prevista na Regra 23 das Normas Federais de Processo Civil Norte Americano, que pode ser compreendido como o correspondente ao nosso CPC/2015: "Inicialmente, trouxemos de lá os dois primeiros modelos existentes na class action norte-americana (Regra 23, B (1) e B (2)), o que, grosso modo, corresponderia a tutela dos direitos difusos e coletivos" (RODRIGUES, 2007, p. 256).

O objetivo central das class action é permitir que um ou mais membros de um determinado grupo ou classe, possam demandar e ser demandados como representantes dessa classe ou grupo em interesses transindividuais. Sendo assim, um indivíduo, ou vários indivíduos poderão demandar, por meio de uma única demanda, a reparação de um determinado dano ambiental por exemplo. Inclusive, permitindo-se a figuração dessa classe também no pólo passivo, o que ensejará a possibilidade de uma ACP passiva (defendant class action).

No entanto, tal assertiva no cenário nacional brasileiro ainda necessita de

\footnotetext{
${ }^{8}$ Defendant class action.
} 
maiores contornos, estudos e discussões, haja vista que o cenário jurídico e social (realidade fática) do Brasil e dos EUA ainda são muito discrepantes.

Sob o enfoque da legitimidade passiva, é aceitável considerar que poderão integrá-la todas aquelas pessoas que tenham contribuído negativamente para o ensejo de dano que tenha motivado a propositura da ACP. Nessa órbita, destaca Meirelles que: "a legitimação passiva estende-se a todos os responsáveis pelas situações ou fatos ensejadores da ação [...]" (MEIRELLES, 2009, p. 204).

Importante asseverar, portanto, que a ACP trata-se de verdadeiro mecanismo processual tendente a consubstanciar a proteção daqueles direitos e interesses difusos e coletivos, sobretudo, aqueles concernentes à proteção e à responsabilização pelo dano causado ao meio ambiente equilibrado, que apresentase como o direito de todos, inclusive das gerações futuras. Em sequência, ater-se-á aos conceitos e preceitos da $\mathrm{AP}$, que ao contrário da ACP premia a participação individual da população na defesa daqueles direitos afetos à sociedade.

\section{A AÇÃO POPULAR AMBIENTAL}

A AP constitui-se como um remédio constitucional expresso no rol do art. 5ำ da CF/88, o que não poderia ser aceito de forma diversa, haja vista que a mesma se mostra como uma ação tendente a propiciar a participação e a fiscalização popular daquelas condutas que atentem contra o patrimônio público, a moralidade administrativa, o meio ambiente e o patrimônio histórico e cultural.

Trata-se, portanto, de verdadeiro instrumento da democracia deliberativa, que possibilita a qualquer do povo participar e requerer o bom funcionamento da administração pública e a devida proteção do meio ambiente equilibrado com o fito de propiciar a sadia qualidade de vida.

Cabe aqui, uma pequena digressão elucidativa sobre democracia deliberativa. A democracia deliberativa pressupõe um maior engajamento dos indivíduos, através da teoria do discurso elaborada e desenvolvida por Jürgen Habermas, segundo o qual:

A produção do direito legítimo através de uma política deliberativa configura, pois, um processo destinado a solucionar problemas, o qual trabalha com saber, ao mesmo tempo em que o elabora, a fim de programar a regulação de conflitos e a persecução de fins coletivos (HABERMAS, 2011, p. 45). 
Nessa perspectiva, a democracia deliberativa admite que os diferentes discursos sociais sejam ouvidos nos mais diversos palcos, restando claro, portanto, que a democracia deliberativa deve permear todo o Estado Democrático de Direito, porque propõe o discurso entre todos os envolvidos.

Torna-se necessário asseverar que as congregações dos direitos inerentes à AP condensam-se em verdadeiros mecanismos deliberativos da vontade popular, ao passo que se mostra como garantia fundamental de procedibilidade conducente a propiciar acesso à justiça social, econômica e ambiental, uma vez que: "o entendimento de que cada cidadão individual é, pelo menos, capaz de decidir o que é bom para si mesmo é uma característica da democracia, como garantia de Igualdade" (SILVA; SANTOS; BARCELOS, 2017, p. 261, tradução própria) ${ }^{9}$.

Noutra vertente, é importante considerar que o surgimento da AP remonta a meados do ano de 1934, ou seja, antes da concreta institucionalização do Estado Democrático de Direito no Brasil que só veio a ocorrer no ano de 1988, quando da promulgação da CF/88. Nesse espeque, Oliveira explica que: "a ação popular encontrou, pela primeira vez, assento constitucional no Brasil através da Carta de 1934, destacando-se os artigos 1ํ e 6” [...] (OLIVEIRA, 2011, p. 38).

A abrangência do texto da Carta de 1946 levou, por oportuno, a elaboração da Lei 4.717/65 que tratou de disciplinar a AP de forma completa e detalhada, a qual encontra-se em vigor até os dias atuais como a base constitutiva da participação democrática por meio da ação popular. Após, a Constituição de 1967 manteve o instituto em seu texto, inclusive pelo o histórico que mesma angariou no cenário nacional.

Em sequência, com a promulgação da $\mathrm{CF} / 88$, a $\mathrm{AP}$ ganhou local de destaque, elevada à condição de garantia fundamental taxativamente expressa no rol dos remédios constitucionais do art. $5^{\circ}$ da $\mathrm{CF} / 88$.

Realizada a útil digressão histórica no contexto da AP, é necessário realçar que foi Barbosa Moreira, o primeiro a destacar a importância da mesma para tutelar os direitos e os interesses difusos. Neste sentido, Grinover destaca que: "enquanto essas novas tendências despontam, vem sendo utilizada, para a tutela de certos interesses difusos, a ação popular constitucional. Foi Barbosa Moreira o primeiro a

${ }^{9}$ The understanding that each individual citizen is at least capable of deciding what is good for himself is a characteristic of democracy, as a guarantee for political equality. 
dar à ação constitucional esse enfoque [...]" (GRINOVER, 1984, p. 297).

Nas palavras de Moreira: "a Lei no 4.717, de 29.06.1965, que disciplinou o processo da ação popular, dotou o nosso ordenamento de meio apto a servir, em larga medida, à proteção judicial de interesses coletivos e difusos [...] (MOREIRA, 1995, p. 194).

Nesse sentir, é possível evidenciar que o objetivo da AP é dotar os indivíduos de poderes reais e legítimos, para, por meio do processo jurisdicional, encaminhar esforços em favor da proteção ao direito fundamental ao meio ambiente ecologicamente saudável e equilibrado. Conosco, coaduna a doutrina: "no direito brasileiro vigente, a participação direta na defesa do meio ambiente, por intermédio do processo jurisdicional, é viabilizada pela ação popular, único instituto processual a admitir, entre nós, a rigor, iniciativas judiciais individuais na matéria" (MIRRA, 2011, p. 230).

Diferentemente da $\mathrm{ACP}$, que não admite no polo ativo o cidadão (indivíduo pessoa física), conforme demonstrado anteriormente, na AP o legitimado ativo é justamente o cidadão. De acordo com o art. 1ำ da Lei 4.717/65, qualquer cidadão será parte legítima para pleitear a anulação ou a declaração de nulidade de atos lesivos ao patrimônio da União, do Distrito Federal, dos Estados e dos Municípios (BRASIL, 1965).

Tanto a Lei quanto a CF/88 usam o termo "cidadão" para identificar aquele legitimado á propositura da ação popular. Nesse ponto, parece haver na doutrina uma reflexão a respeito do fato de que somente aquele cidadão no exercício de seus direitos políticos estaria legitimado a propor a AP, ou seja, somente aquele nacional que esteja em plenas condições de votar e de ser votado. Não para menos, haja vista que o $\S 3^{\circ}$, do art. 1ำ da Lei 4.717/65, dispõe que: "§ 3ํA prova da cidadania, para ingresso em juízo, será feita com o título eleitoral, ou com documento que a ele corresponda" (BRASIL, 1965).

Com o objetivo de trazer a questão à baila, aponta Mirra que: "tradicionalmente, entende-se por cidadão, como sujeito legitimado à propositura de demandas populares, o indivíduo nacional que esteja no exercício dos direitos políticos" (MIRRA, 2011, p. 231).

No entanto, maior parte da doutrina não coaduna com essa afirmação. No que tange à proteção do meio ambiente, entendemos que o conceito de cidadão não pode ser restrito àqueles indivíduos que estejam em gozo dos seus direitos políticos, 
pois a CF/88 consagrou no art. 5ㅇ 0 rol de direitos e garantias fundamentais inerentes ao indivíduo (pessoa humana), independentemente de estar ou não em gozo dos direitos políticos. $O$ direito ao meio ambiente equilibrado à sadia qualidade de vida, que está previsto no art. 225 da CF/88, consagra o direito fundamental ao meio ambiente saudável que se confunde com o próprio direito à vida e, portanto, deve ser protegido e preservado por todos os indivíduos e pelo o Estado. Deste modo, sua proteção não pode ficar mitigada à prova dos direitos políticos, sob pena de retrocesso na esfera protecionista do bem difuso.

$\mathrm{Na}$ esteira desse entendimento caminha Fiorillo: "[...] nada mais lógico que não só o eleitor quite com a Justiça Eleitoral, mas todos os brasileiros e estrangeiros residentes no País possam ser rotulados cidadãos para fins de propositura da ação popular ambiental" (FIORILLO, 2013, p.473).

Outro aspecto importante e que merece destaque, é o fato de que o pretenso promotor da AP estará isento de custas processuais e de ônus sucumbenciais, conforme expresso na parte final do art. $5^{\circ}, \mathrm{LXXIII}$, da CF/88. Essa isenção de custas faz superar uma das barreiras do acesso à justiça, apontadas por Cappelletti e Garth: "um exame dessas barreiras ao acesso, como se vê, revelou um padrão: os obstáculos criados por nossos sistemas jurídicos são mais pronunciados para as pequenas causas e para os autores individuais, especialmente os pobres [...]" (CAPPELLETTI; GARTH, 1988, p. 28).

Nesse passo, a norma constitucional que garante a isenção para o ajuizamento da AP pretende propiciar a primeira solução para o acesso à justiça, a qual Cappelletti e Garth descrevem como a primeira 'onda' de acesso à justiça: "os primeiros esforços importantes para incrementar o acesso à justiça nos países ocidentais concentraram-se, muito adequadamente, em proporcionar serviços jurídicos para os pobres" (CAPPELLETTI; GARTH, 1988, p. 31-32). ${ }^{10}$

Nessa perspectiva, Stephen e Sunstein destacam que:

Proporcionar aos cidadãos acesso a tribunais e outros fóruns judiciais não é como dar-lhes acesso a portos naturais e águas navegáveis, porque o governo não deve apenas por de lado os obstáculos ao acesso, mas deve realmente criar as instituições às quais o acesso está sendo concedido

\footnotetext{
10 Cappelletti e Garth apontam três ondas de solução do acesso à justiça: A primeira onda de acesso à justiça se concentra em oportunizar a assistência judiciária gratuita. A segunda onda em oportunizar a representação jurídica para os interesses difusos, especialmente em matérias de proteção ambiental e do consumidor. A terceira onda está fixada no enfoque de acesso à justiça (CAPPELLETTI; GARTH, 1988, p. 31).
} 
(STEPHEN; SUNSTEIN, 1999, p. 54, tradução própria) ${ }^{11}$.

Portanto, diante desse avanço promovido pela $\mathrm{CF} / 88$, que acabou por superar uma das barreiras do acesso à justiça, é possível compreender que o cidadão (indivíduo) detém plenas condições de atuar em favor do meio ambiente, de modo a promover, na esfera jurisdicional, a AP com vistas a atender os direitos e interesses difusos e coletivos.

\section{AMICUS CURIAE: INSTRUMENTO DE PARTICIPAÇÃO E FISCALIZAÇÃO NO PROCESSO COLETIVO AMBIENTAL?}

Até o momento, o presente estudo cuidou de apresentar um breve desenvolvimento histórico sobre o amicus curiae. Após, foram apontados os avanços promovidos com a codificação do referido instituto no âmbito do CPC/2015. Posteriormente, foram trazidas à baila, de maneira breve, a ACP e seus desdobramentos, bem como a AP e suas nuances, no intuito de expor dois dos instrumentos mais trabalhados na seara do processo coletivo ambiental. Essa breve incursão nesses institutos foi necessária do ponto de vista acadêmico e metodológico, uma vez que no presente capítulo serão condensados todos os institutos anteriormente trabalhados, de modo a tentar desvelar e obter uma resposta adequada ao problema levantado neste ensaio, sem, contudo, nenhuma pretensão de esgotar a vasta discussão.

Em primeira linha merece destaque o fato de que na contemporaneidade os rumos do direito constitucional ganharam novos contornos e novas alegorias a serem desenvolvidas. A pós-modernidade consubstancia-se em um novo paradigma constitucional voltado para um maior comprometimento e desenvolvimento do texto constitucional, tendente, em boa medida, a realizar a concreta implementação dos direitos e garantias fundamentais.

No cenário nacional o novo constitucionalismo democrático, ou neoconstitucionalismo democrático, vem ganhando cada vez mais adeptos, no intróito de promover uma reinterpretação do sistema jurídico pelas lentes da $\mathrm{CF} / 88$, que propaga sua força normativa. Nesses termos, ensina Barroso:

\footnotetext{
11 Giving citizens access to courts and other adjudicative forums is not like giving them access to natural harbors and navigable waters, because the government must not only brush aside hindrances to access, but must actually create the institutions to which access is being granted.
} 
Em suma: o neoconstitucionalismo ou novo direito constitucional, na acepção aqui desenvolvida, identifica um conjunto amplo de transformações ocorridas no Estado e no direito constitucional, em meio às quais podem ser assinalados, (i) como marco histórico, a formação do Estado constitucional de direito, cuja consolidação se deu ao longo das décadas finais do século XX; (ii) como marco filosófico, o pós-positivismo, com a centralidade dos direitos fundamentais e a reaproximação entre Direito e ética; e (iii) como marco teórico, o conjunto de mudanças que incluem a força normativa da Constituição, a expansão da jurisdição constitucional e o desenvolvimento de uma nova dogmática da interpretação constitucional. Desse conjunto de fenômenos resultou um processo extenso e profundo de constitucionalização do Direito (BARROSO, 2006, p. 29).

Nesse contexto, a força normativa da $\mathrm{CF} / 88$ pretende empreender um maior alcance das normas constitucionais, de modo a imprimir uma aplicação e interpretação expansiva de seu texto. A CF/88, portanto, assume papel central no ordenamento jurídico em razão de possuir um significado próprio de pujança de normatividade. Dessa maneira, explica Hesse que a Constituição jurídica tem significado próprio: "sua pretensão de eficácia apresenta-se como elemento autônomo no campo de forças do qual resulta a realidade do Estado. A Constituição adquire força normativa na medida em que logra idealizar essa pretensão de eficácia" (HESSE, 1991, p. 15/16).

A par desses avanços advindos do novo constitucionalismo e, sobretudo, da necessidade de responder aos novos direitos emergidos na sociedade pós-moderna, o direito processual vai aos poucos abandonando sua vertente individualista para ceder espaço ao direito processual coletivo.

Nessa perspectiva, Cambi e Damasceno explicam que: "tal ramo assume feição principiológica particular e exige a experimentação de conceitos, menos formalistas, diferentes daqueles impostos, pelo CPC, à solução de conflitos de interesses individuais" (CAMBI; DAMASCENO, 2015, p. 656).

Em meio às modificações no cenário do direito processual nacional, o amicus curiae ganha maior relevância no contexto do direito processual coletivo, principalmente depois que o $\mathrm{CPC} / 2015$ tratou de codificá-lo. Ainda assim, o $\mathrm{CPC} / 2015$, ao inaugurar novas regras, típicas do sistema jurídico da common law, no sistema brasileiro, e, aqui, trata-se daquelas normas que exprimem a padronização do direito pela força vinculante dos precedentes, passa a depender de uma legitimação adequada dessas decisões. Nessa perspectiva o amicus curiae se apresenta como instituto apto a entregar maior legitimidade ao Poder Judiciário, que 
agora exara decisões que vinculam todo o ordenamento jurídico.

Isso porque, no Estado Democrático de Direito todo poder emana do povo, conforme corrobora a doutrina: "[...] no moderno estágio de evolução da doutrina, todo poder é uno no Estado e emana do povo, sendo apenas distribuídas as funções pelos diversos órgãos do Executivo, do Legislativo e do Judiciário" (ZANETI JR, 2013, p. 48).

A legitimidade decorrente do amicus curiae está balizada no princípio da participação democrática, premissa inarredável na formação dos precedentes. Inclusive, o devido processo legal, calcado na isonomia, na ampla defesa, no contraditório e na fundamentação das decisões, são premissas inafastáveis para a formulação de todo e qualquer precedente, sendo que o CPC/2015, como dito anteriormente, aproximou a norma processual dos preceitos concernentes à processualidade democrática.

Tratando-se de demandas coletivas de natureza ambiental, compreende-se que a participação oportunizada pelo amicus curiae, efetiva, parcialmente, o preceito constitucional previsto no art. 225 da CF/88. Em outras palavras, o direito ao meio ambiente equilibrado a sadia qualidade de vida, consubstancia-se em um direito fundamental de caráter intra e intergeracional, onde a coletividade tem 0 dever/direito de protegê-lo e preservá-lo para as presentes e futuras gerações.

Para tanto, Gomes e Ferreira destacam que, "para isso, é requerida uma ação da sociedade, das organizações civis e dos governos no sentido de promover mecanismos que possam tutelar o meio ambiente equilibrado à sadia qualidade de vida intergeracional" (GOMES; FERREIRA, 2017, p. 98).

Nada mais adequado, portanto, que naquelas demandas coletivas de natureza ambiental a sociedade possa ser chamada a participar e a fiscalizar os rumos do processo, uma vez que, diante da vinculação dos precedentes, uma decisão tomada em sede de recurso repetitivo irá produzir efeitos para todo um grupo de indivíduos e quiçá para todo ordenamento jurídico. Assim, o amicus curiae desponta como um instrumento parcialmente adequado a propiciar a intervenção e a fiscalização social nos processos coletivos ambientais.

Isso porque, para que o amicus curiae possa eclodir como um instrumento integralmente adequado a propiciar a intervenção e a fiscalização social nos processos coletivos ambientais, um avanço epistemológico e teórico do instituto se mostra indispensável. Em outros termos, o amicus curiae, conforme disciplinado no 
art. 138 do CPC/2015, afigura-se como instrumento adequado a fornecer subsídios técnicos ao julgador da demanda, por isso a doutrina sistematicamente o denomina de 'amigo da corte'.

Nesse sentir, a utilidade do instituto está mais inclinada a fornecer subsídios técnicos para municiar o julgador, do que propriamente oportunizar a participação democrática na demanda. Assim, a participação social no âmbito do amicus curiae é uma consequência prática da intervenção da tecnicidade, que é indispensável à resolução daquelas demandas complexas. Desta feita, o amicus curiae é um instrumento parcialmente democrático, pois sua participação é autorizada para fomentar o julgador de conteúdos técnicos, tanto que, repita-se, trata-se de um 'amigo da corte'. Não é, portanto, instituto puramente democrático. Ao falar do amicus curiae como uma figura puramente democrática o ideal seria utilizar a nomenclatura de 'um amigo da democracia'.12

No entanto, justiça deve feita ao instituto, pois apesar de ser chamado a intervir na demanda somente para fornecer subsídios técnicos à resolução da causa, ele também acaba por ocasionar, de forma parcial e acessória, a participação e a fiscalização social do pleito.

Contudo, no Estado Democrático de Direito, a participação social deve ser oportunizada por meio de mecanismo próprio e não simplesmente admitida como parte acessória do agente técnico. A participação democrática não pode ficar adstrita ao segundo plano, ao contrário, o debate democrático deve ser oportunizado via mecanismo próprio comprometido com a legitimidade democrática.

Nesse viés, o presente ensaio pretende sugerir a elaboração de um agente democrático (não estatal), terceiro interessado em prol da coletividade (amicus curiae democrático - com representatividade adequada: pro natura e pro societatis), para efetivação da participação social mediante o debate democrático. Trata-se de um agente democrático comprometido única e exclusivamente com a participação social na formação dos precedentes judiciais em matéria ambiental, trata-se de 'um amigo da democracia'.

Dado que, no atual desenvolvimento da matéria, no que tange ao meio ambiente e à participação democrática, a doutrina vem avançando no sentido de que o direito fundamental à participação não está conexo somente àquela ideia de

\footnotetext{
${ }^{12}$ Do Latim: Amicum ex democratia.
} 
democracia-representativa efetivada por meio do sufrágio universal. Ao contrário, o avanço epistemológico da matéria evidencia uma real participação denominada de democracia-participativa, de modo a permitir e a demandar plena aproximação da sociedade civil com aquelas decisões políticas que the são inerentes. Assim, "Na conformação intersubjetiva dos conteúdos dos direitos e deveres fundamentais, toda a sociedade deve estar envolvida por meio de participação democrática direta, sempre que viável" (MARCO; MEZZAROBA, 2017, p. 335).

A evolução da democracia-participativa está diametralmente ligada ao avanço dos direitos fundamentais e suas dimensões. Na mesma ótica, confirmam Sarlet e Fensterseifer que, "a democracia, portanto, não se esgota no voto. A democracia é um conceito jurídico, mas, mais do que isso, é uma práxis políticojurídica em constante aprimoramento e consolidação" (SARLET; FENSTERSEIFER, 2015, p. 711).

No mesmo compasso, afirma Bonavides: "não há teoria constitucional de democracia participativa que não seja, ao mesmo passo, uma teoria material da Constituição" (BONAVIDES, 2001, p. 25).

Portanto, a democracia-participativa deve ser também oportunizada no âmbito do processo coletivo ambiental, haja vista que a sociedade deve ter a oportunidade concreta de cooperar, colaborar, compartilhar e envolver-se nas demandas ambientais, haja vista tratar-se de bem difuso pertencente a todos os indivíduos. Na mesma lógica de democracia-participativa é de bom alvitre considerar que a elaboração do amicus curiae democrático - com representatividade adequada: pro natura e pro societatis, se mostra como instrumento adequado a promover a participação social no processo coletivo ambiental.

Por outro lado, conforme exposto no capítulo anterior, o art. 138 do $\mathrm{CPC} / 2015$, ao dispor sobre o amicus curiae, apresenta alguns requisitos para que a intervenção seja permitida, os quais serão tratados com o objetivo de condensar a pesquisa.

O art. 138, caput assevera que cabe ao juiz ou ao relator, considerando a relevância da matéria, a especificidade do tema objeto da demanda ou a repercussão social da controvérsia, admitir, de ofício ou a requerimento das partes ou de quem pretenda manifestar-se, a participação de pessoa natural ou jurídica, órgão ou entidade especializada, com representatividade adequada.

O fato de caber ao 'juiz ou ao relator' decidir sobre a intervenção indica que 
o amicus curiae poderá atuar em quaisquer instâncias do Poder Judiciário, o que é positivo, principalmente se tratando de processo coletivo ambiental, pois a participação deve ocorrer durante todo o procedimento para que as adequadas razões sejam levadas ao conhecimento do julgador, tanto aquelas de caráter técnico quanto aquelas puramente democráticas.

Em relação aos requisitos relevância da matéria, especificidade do tema, repercussão geral da matéria, os mesmos indicam que não será permitida a intervenção do amicus curiae em toda e qualquer demanda, uma vez que a demanda necessita ter um viés mais coletivo, que venha a produzir efeitos para um determinado grupo ou classe da sociedade. No entanto, isso não indica que uma demanda individual não permitir a intervenção do amicus curiae, pois em alguns casos uma demanda individual poderá representar modificações no cenário de toda uma coletividade. No processo coletivo ambiental parece não haver maiores indagações, haja vista que toda demanda ambiental se mostra relevante, de objeto específico e de grande repercussão social.

No que tange à possibilidade de ser feita a intervenção em razão de requerimento das partes ou de ofício, constata-se que as duas opções são viáveis e aceitas sendo que tanto a pedido do juiz ou do relator, das partes, ou de quem tenha interesse em intervir, poderá ser admitida a intervenção do amicus curiae. Esse requisito mostra-se bastante amplo e pretende a real democratização da demanda, haja vista que estão autorizados a requer a intervenção, tanto aqueles que estão compondo a demanda (dentro da demanda), quanto aqueles interessados que estão fora dela.

O fato de admitir a participação de pessoa natural ou jurídica, de órgão ou entidade especializada, com representatividade adequada, apresenta-se como verdadeiro requisito legitimador da democracia-participativa ou democraciadeliberativa, uma vez que permite a intervenção até mesmo de pessoas físicas na lide, desde que detenham representatividade adequada. Nesse ponto, destaca Bueno que:

Exige-se do amicus curiae, que poderá ser pessoa natural ou jurídica, órgão ou entidade especializada, "representatividade adequada", isto é, que mostre satisfatoriamente a razão de sua intervenção e de que maneira seu "interesse institucional" - que é o traço distintivo desta modalidade interventiva, que não se confunde com o "interesse jurídico" das demais modalidades interventivas - relaciona-se com o processo. (BUENO, 2015, p. 158). 
Portanto, o amicus curiae não pode ser admitido para atuar em causa própria, muito ao contrário, ele deve ser admitido para atuar em nome de uma coletividade com o objetivo de fiscalizar e colaborar com a formação do provimento final a fim de tornar a decisão plenamente democrática, daí a necessidade da intervenção de um amicus curiae democrático - amigo da democracia.

Visto que, "participação constrói credibilidade e legitimidade de políticas, planos e decisões aos olhos da comunidade e garante maior propriedade e conformidade" (PRANEETHA, 2013, p. 96, tradução própria) ${ }^{13}$.

Afigura-se, portanto, que a admissão do amicus curiae democrático irá propiciar uma discussão mais descentralizada da demanda, de modo que as várias manifestações poderão contribuir para a prolação de uma decisão mais justa, equânime e democrática, uma vez que na seara ambiental tal premissa é inarredável e se coaduna com o ideal de democracia-deliberativa.

\section{CONSIDERAÇÕES FINAIS}

Ao final deste estudo, foi possível considerar que nos últimos anos o direito tem avançado rumo a encontrar novos caminhos e rumos para superar os desafios inerentes às sociedades modernas. A população mais conhecedora de seus direitos a cada dia vem buscar a concreta implementação dos seus interesses, inclusive aqueles de ordem difusa, que dizem respeito a toda uma coletividade.

Em função disso, o direito processual amoldou-se às novas facetas sociais, abandonando aos poucos aquelas antigas bases individuais para pensar um novo processo civil. Um processo civil voltado a transmitir a vontade da coletividade vem ganhando, aos poucos, espaço na esfera internacional e nacional. $\mathrm{Na}$ esfera nacional, a CF/88 inaugurou um novo cenário democrático, um cenário em que o sistema jurídico se rende à força normativa dos preceitos constitucionais, na qual os princípios constitucionais tornam-se o centro do sistema jurídico e base sólida tendente a irradiar normas que orientem todos os ramos do direito.

Nessa perspectiva, surge então 0 que se denomina de novo constitucionalismo, ou neoconstitucionalismo, sendo entendido como aquele que se

\footnotetext{
${ }^{13}$ Participation builds the credibility and legitimacy of policies, plans and decisions in the eyes of the community, and ensures greater ownership and compliance.
} 
preocupa em efetivar os direitos e garantias fundamentais, sem, contudo, se distanciar da premissa de que todo o poder emana do povo, que o exerce por meio da democracia-deliberativa. O processo civil, também permeado pela força normativa da $\mathrm{CF} / 88$ e pelo neoconstitucionalismo, reestrutura suas bases acerca da processualidade democrática, em detrimento daquela teoria que entende o processo como mera relação jurídica.

Esse avanço epistemológico foi mais perfeitamente observado a partir da entrada em vigor do CPC/2015, que, dentre outros benefícios, apresentou um novo processo civil destinado e aberto há uma nova espécie de processualidade, prestigiando o paradigma jurídico da discursividade dialética e potencializando o devido processo legal, a isonomia, o contraditório, a ampla defesa e a fundamentação das decisões. Codifica-se, portanto, o processo como instituição constitucionalizada.

O CPC/2015 também dotou o sistema jurídico brasileiro de normas e teorias de afeições típicas do sistema jurídico da common law. Em especial modificação, o CPC/2015 importou dos americanos para o sistema jurídico brasileiro a teoria do stare decisis, onde os precedentes judiciais fundamentam casos análogos no futuro, objetivando o processo subjetivo. Agora o Poder Judiciário exara decisões que vinculam todo o sistema jurídico, sendo indispensável à oportunização de espaços adequados para a manifestação da sociedade, justamente para oferecer maior legitimidade aos precedentes judiciais.

Nessa seara, o amicus curiae se apresenta como instrumento apto a realizar essa dicotomia e entregar maior legitimidade aos precedentes judiciais, uma vez que a sociedade é chamada a participar e a fiscalizar o provimento final que irá vincular todo o sistema jurídico.

No que concerne ao processo coletivo ambiental o problema se assemelha, a CF/88 determinou de forma clara e contunde que é um dever e um direito de toda a sociedade e do Estado promover a proteção e preservação do meio ambiente equilibrado à sadia qualidade de vida. Nessa ótica, imprescindível a participação da sociedade naquelas demandas que versem sobre o meio ambiente saudável, uma vez que se trata de direito difuso inerente a toda a coletividade.

Nessa perspectiva, no intróito de resolver o problema posto em análise, apresentou-se que no Estado Democrático de Direito, onde a democraciaparticipativa deve ser profundamente conduzida e oportunizada, o amicus curiae se 
apresenta como instrumento parcialmente democrático, tendente a propiciar uma adequada participação e fiscalização das decisões judiciais, exaradas no âmbito do processo coletivo ambiental.

Embora não tenha a pretensão de esgotar esse vasto e intrigante assunto, haja vista que tratar de amicus curiae, democracia e meio ambiente equilibrado é deveras uma missão a ser desvelada pelos estudiosos do tema, pois parte-se da premissa de que a promoção do meio ambiente equilibrado à sadia qualidade de vida depende de uma séria e comprometida participação social.

Essa efetiva participação social só se dará de forma plena com o desenvolvimento nuclear da democracia-deliberativa, onde os mecanismos existentes sejam devidamente postos à disposição da sociedade. Nessa órbita a pesquisa sugere uma forma mais efetiva de participação social no processo civil ambiental, para além do amicus curiae tradicional, qual seja a elaboração de políticas públicas adequadas a permitir e evidenciar a intervenção de um agente democrático (não estatal), terceiro interessado em prol da coletividade (amicus curiae democrático - com representatividade adequada: pro natura e pro societatis), trata-se de um amigo da democracia, para efetivação da participação social na defesa do meio ambiente, de modo a fomentar o debate democrático.

Assim, é necessário um avanço teórico no que tange ao amicus curiae tradicional e tecnicista, de modo a permitir a inauguração de um novo espaço democrático (amicus curiae democrático - amigo da democracia), de modo a permear o Estado Democrático de Direito e seus Poderes Executivo, Legislativo e Judiciário, de plena legitimação democrática com implementação de um diálogo institucional.

Ao passo que, por hora, o amicus curiae expresso no âmbito do CPC/2015, cumpre parcialmente a missão de oportunizar a toda sociedade um debate sincero e nuclear daquelas demandas que versem sobre o direito fundamental ao meio ambiente equilibrado, que é por excelência um bem difuso e coletivo. No entanto, o avanço na elaboração e no desenvolvimento de uma figura estritamente participativa, conforme sugerido no presente estudo, qual seja, o instituto do amicus curiae democrático - amigo da democracia, é uma premissa inarredável de conformação da democracia-participativa e deliberativa em prol da defesa do meio ambiente equilibrado à sadia qualidade de vida. 


\section{REFERÊNCIAS}

BARROSO, Luís Roberto. Neoconstitucionalismo e constitucionalização do direito: o triunfo tardio do direito constitucional no Brasil. Revista da ESMEC, Fortaleza, v.4. oㅡ 2, p. 11-100, 2006. Disponível em:

<http://revistathemis.tjce.jus.br/index.php/THEMIS/article/view/241/232>. Acesso em: 05 maio 2018.

BONAVIDES, Paulo. Teoria constitucional da democracia participativa. 2. ed. São Paulo: Malheiros, 2001.

BRASIL. Constituição da República Federativa do Brasil 1988. Diário Oficial da União, Brasília, 05 out. 1988. Disponível em:

<http://www.planalto.gov.br/ccivil_03/Constituicao/Constituicao.htm>. Acesso em: 05 maio 2018.

BRASIL. Lei o 4.717, de 29 jun. 1965. Regula a ação popular. Diário Oficial da União, Brasília, 29 jun. 1965. Disponível em:

<http://www.planalto.gov.br/ccivil_03/leis//4717.htm>. Acesso em: 05 maio 2018.

BRASIL. Lei $n^{\circ}$ 6.938, de 31 de ago. 1981. Dispõe sobre a Política Nacional do Meio Ambiente, seus fins e mecanismos de formulação e aplicação, e dá outras providências. Diário Oficial da União, Brasília, 02 set. 1981. Disponível em: <http://www.planalto.gov.br/ccivil_03/Leis/L6938.htm>. Acesso em: 05 maio 2018.

BRASIL. Lei no 7.347, de 24 jul. 1985. Disciplina a ação civil pública de responsabilidade por danos causados ao meio-ambiente, ao consumidor, a bens e direitos de valor artístico, estético, histórico, turístico e paisagístico e dá outras providências. Diário Oficial da União, Brasília, 25 jul. 1985. Disponível em: <http://www.planalto.gov.br/ccivil_03/leis//7347orig.htm>. Acesso em 05 maio 2018.

BRASIL. Lei no 10.259, de 12 jul. 2001. Dispõe sobre a instituição dos Juizados Especiais Cíveis e Criminais no âmbito da Justiça Federal. Diário Oficial da União, Brasília, 12 jul. 2001. Disponível em: <http://www.planalto.gov.br/ccivil_03/Leis/LEIS_2001/L10259.htm>. Acesso em: 01 jun. 2018.

BRASIL. Lei no 13.105 de 16 mar. 2015. Código de Processo Civil. Diário Oficial da União, Brasília, 17 mar. 2015. Disponível em:

<http://www.planalto.gov.br/ccivil_03/_ato2015-2018/2015/lei/13105.htm>. Acesso em: 05 maio 2018.

BUENO, Cassio Scarpinella. Amicus curiae no processo civil brasileiro: um terceiro enigmático. 3. ed. São Paulo: Saraiva, 2012.

BUENO, Cassio Scarpinella. Amicus curiae no projeto de novo Código de Processo Civil. Revista de Informação Legislativa, Brasília, v. 48, ํo 190, p. 111-121, abr.jjun. 2011. Disponível em: <http://www2.senado.leg.br/bdsf/bitstream/handle/id/242885/000923086.pdf?sequen $\mathrm{ce}=1$ > . Acesso em: 05 maio 2018. 
BUENO, Cassio Scarpinella. Manual de direito processual civil: inteiramente estruturado à luz do novo CPC - Lei no 13.105, de 16-03-2015. São Paulo: Saraiva, 2015.

CABRAL, Antônio do Passo. Do amicus curiae. In: STRECK, Lênio Luiz; NUNES, Dierle; CUNHA, Leonardo Carneiro da. (Coord.). Comentários ao Código de Processo Civil: de acordo com a Lei 13.256/2016. São Paulo: Saraiva, 2016. Cap. V, p. 330-340.

CABRAL, Antônio do Passo. Pelas asas de Hermes: a intervenção do amicus curiae, um terceiro especial. Revista de Direito Administrativo, Rio de Janeiro, v. 234, p. 111-141, out./dez. 2003. Disponível em:

<http://bibliotecadigital.fgv.br/ojs/index.php/rda/article/view/45149/44793>. Acesso em: 05 maio. 2018.

CAMBI, Eduardo; DAMASCENO, Kleber Ricardo. Amicus curiae e o processo coletivo: uma proposta democrática. In: CLÉVE, Clémerson Merlin (Coord.). Direito constitucional: processo constitucional. São Paulo: Revista dos Tribunais, 2015. Tomo I, Cap. IV, p. 655-687.

CAPPELLETTI, Mauro; GARTH, Bryant. Acesso à justiça. Tradução por Ellen Gracie Northfleet. Porto Alegre: Fabris, 1988.

CHIOVENDA, José. Principios de derecho procesal civil. Tradução por José Casais Y Santaló. Madrid: Reus, 1922.

COSTA, Rosalina Moitta Pinto da. O amicus curiae como instrumento de participação democrática e de realização dos direitos fundamentais. Revista Jurídica da Presidência, Brasília, v. 15, no 106, p. 339-372, jun./set. 2013. Disponível em: $<$ https://revistajuridica.presidencia.gov.br/index.php/saj/article/view/82/73>. Acesso em: 05 maio 2018.

FIGUEIREDO, Apoliana Rodrigues. Amicus curiae estudo do artigo 138 do Código de Processo Civil. Revista Pensamento Jurídico, São Paulo, v. 11, no 2, p. 239261, jul/dez. 2017. Disponível em:<http://www.fadisp.com.br/revista/ojs/index.php/pensamentojuridico/article/view/1 08/153 >. Acesso em: 05 maio. 2018.

FIORILLO, Celso Antônio Pacheco. Curso de direito ambiental brasileiro. 14. ed. São Paulo: Saraiva, 2013.

GOMES, Magno Federici; FERREIRA, Leandro José. A dimensão jurídico-política da sustentabilidade e o direito fundamental à razoável duração do procedimento.

Revista do Direito, Santa Cruz do Sul, no 52, v. 2, p. 93-111, maio/ago. 2017. Disponível em: <http://dx.doi.org/10.17058/rdunisc.v2i52.8864>. Acesso em: 17 abr. 2018.

GRINOVER, Ada Pellegrini. Novas Tendências na Tutela Jurisdicional dos 
Interesses Difusos. Revista da Faculdade de Direito da USP, São Paulo, v. 79, p. 283-307, 1984. Disponível em:

<https://www.revistas.usp.br/rfdusp/article/view/67016/69626>. Acesso em: 05 maio 2018.

HÄBERLE, Peter. Hermenêutica constitucional: a sociedade aberta dos intérpretes da Constituição: contribuição para interpretação pluralista e "procedimental" da Constituição. Revista Direito Público, v. 11, no 60, p. 25-50, abr. 2015. Disponível em:

<https://www.portaldeperiodicos.idp.edu.br/direitopublico/article/view/2353/1204>. Acesso em: 25 jun. 2018.

HABERMAS, Jürgen. Direito e democracia: entre facticidade e validade II. Tradução por Flávio Beno Seibeneichler. Rio de Janeiro: Tempo Brasileiro, 2011. vol. 2.

HESSE, Konrad. A força normativa da constituição. Tradução por Gilmar Ferreira Mendes. Porto Alegre: Fabris, 1991.

HOLMES, Stephen; SUNSTEIN, Cass R. The cost of rights: why liberty depends on taxes. New York: W.W. Norton \& Company, 1999. Disponível em: <file:///C:/Users/cdggg/Downloads/5.O.2\%20HOLMES\%3B\%20SUNSTEIN.\%20The $\% 20$ Cost\%20of\%20Rights\%20(ate\%20p\%2083)\%20(1).pdf>. Acesso em: 01 jun. 2018.

MANCUSO, Rodolfo de Camargo. Ação civil pública: em defesa do meio ambiente, do patrimônio cultural e dos consumidores: Lei 7.347/1985 e legislação complementar. 13. ed. São Paulo: Revista do Tribunais, 2014.

MARCO, Cristhian Magnus de; MEZZAROBA, Orides. O direito humano ao desenvolvimento sustentável: contornos históricos e conceituais. Veredas do Direito, Belo Horizonte, v. 14, no 29, p. 323-349, out. 2017. Disponível em: <http://www.domhelder.edu.br/revista/index.php/veredas/article/view/1066/623>. Acesso em 05 maio 2018.

MATTOS, Ana Letícia Queiroga de. Amicus curiae: hermenêutica e jurisdição constitucional. Belo Horizonte: Arraes, 2011.

MEIRELLES, Hely Lopes; WALD, Arnoldo; MENDES, Gilmar Ferreira.Mandado de segurança e ações constitucionais. 32. ed. São Paulo: Malheiros, 2009. MIRRA, Ảlvaro Luiz Valery. Participação, processo civil e defesa do meio ambiente. São Paulo: Letras Jurídicas, 2011.

MOREIRA, José Carlos Barbosa. Ação civil pública e programação da TV. Revista de Direito Administrativo, Rio de Janeiro, v. 201, p. 45-56, jul./set. 1995.

Disponível em: <http://bibliotecadigital.fgv.br/ojs/index.php/rda/article/viewFile/46567/46391>. Acesso em: 05 maio 2018.

MOREIRA, José Carlos Barbosa. Os novos rumos do processo civil brasileiro. In: 
BARBOSA MOREIRA, José Carlos. Temas de direito processual: sexta série. São Paulo, Saraiva, 1997. p. 193-208. Disponível em:

<http://www.ablj.org.br/revistas/revista6/revista6\%20\%20JOS\%C3\%89\%20CARLOS \%20BARBOSA\%2OMOREIRA\%20-

\%200s\%20Novos\%20Rumos\%20do\%20Processo\%20Civil\%20Brasileiro.pdf>. Acesso em: 05 maio 2018.

OLIVEIRA, Adauto José de. Ação popular ambiental. Belo Horizonte: Arraes, 2011.

PRANEETHA, S B. Peoples Participation and Environmental Protection. Journal Of Business Management \& Social Sciences Research, [S.I.], v. 2, n. 2, p. 94-98, feb. 2013. ISSN 2319-5614. Disponível em:

<http://borjournals.com/a/index.php/jbmssr/article/view/174>. Acesso em: 08 jun. 2018.

RODRIGUES, Marcelo Abelha. Ação civil pública. In: DIDIER JR, Fredie. (Coord.). Ações constitucionais. 2. ed. Salvador: Juspodivm, 2007. p. 248-315.

RODRIGUES, Marcelo Abelha. Manual de direito processual civil. 6. ed. Rio de Janeiro: Forense, 2016.

SARLET, Ingo Wolfgang; FENSTERSEIFER, Tiago. Democracia participativa e participação pública como princípios do Estado socioambiental de direito. In: CLÉVE, Clémerson Merlin (Coord.). Direito constitucional: processo constitucional. São Paulo: Revista dos Tribunais, 2015. Tomo I, Cap. IV, p. 709-757.

SILVA, Adriana; SANTOS Polianna; BARCELOS, Júlia. Democracia e informação: o voto nulo no Brasil. Revista Direitos Fundamentais e Democracia - RDFD, Curitiba, v. 22, № 1, p. 257-277, jan./abr. 2017. Disponível em:

<http://revistaeletronicardfd.unibrasil.com.br/index.php/rdfd/article/view/726/496>. Acesso em: 05 jun. 2018.

SILVA, João Henrique Sampaio da. O instituto do amicus curiae e sua atuação no incidente de resolução de demandas repetitivas. In: CASTRO, João Antônio Lima (Coord.). Direito processual e público. Belo Horizonte: PUC Minas, 2018. p. 659670.

THEODORO JÚNIOR, Humberto. Código de processo civil anotado. 20. ed. Rio de Janeiro: Forense, 2016.

ZANETI JÚNIOR, Hermes. A teoria da separação de poderes e o estado democrático constitucional: funções de governo e funções de garantia. In: GRINOVER, Ada Pellegrini; WATANABE, Kazuo (Coord.). O controle jurisdicional de políticas públicas. 2. ed. Rio de Janeiro: Forense, 2013. p. 33-72. 